DOI 10.37882/2223-2982.2020.10.07

\title{
ЛИНГВОКУЛЬТУРОЛОГИЧЕСКИЙ АНАЛИЗ РУССКИХ ПАРЕМИЙ О ТРУДЕ
}

\section{LINGUISTIC AND CULTURAL ANALYSIS OF RUSSIAN PARAMIA ON LABOUR}

L. Bosova

Summary: This article analyzes Russian paramia, revealing the concept of «labour». Being one of the basic components in any conceptual picture, this concept most fully reflects the realities of nation's life and culture. This fact proves the relevance and value of the study. The analysis of Russian paramia showed that they ambiguously reveal the attitude to work in Russian culture: on the one hand, they affirm a positive attitude to work $(11 \%)$, on the other hand, about the same number of proverbs and sayings (10\%) realize a negative attitude to work, denial of its social importance, even contempt.

Keywords: paremia, proverbs, sayings, linguistic and cultural analysis, mentality.

\section{Пословишы и поговорки как объект изучения в ^ингвистике}

$\Pi$ аремии - это веками сложившийся язык обыденной культуры народа, в котором в краткой форме отражены категории и установки жизненной философии нации как носителя данного конкретного языка. Они включают пословицы и поговорки, которые передают как бытовые и социальные, так и философские, религиозные, морально-этические и эстетические взгляды, характерные для той или иной страны, реагируют на все без исключения явления действительности, охватывая практически все сферы человеческой жизни. Паремии являются неотъемлемой частью культуры любого народа, отражением социальных ценностей и чувств людей, сопровождают человечество на протяжении долгих времен.

Пословицы и поговорки многообразны, они находятся как бы вне времени, оставаясь актуально употребительными в любом временном пространстве. Они отражают богатый исторический опыт народа, представления, связанные с трудовой деятельностью, бытом и культурой людей. Правильное и уместное использование пословиц и поговорок придает речи неповторимое своеобразие и особую выразительность.

Вышеизложенное дает полное основание утверждать, что народная мудрость как источник самобытности национальных культур и древнейший пласт любого языка, несомненно, вызывает научно-исследовательский

\author{
Босова Людмила Михайловна \\ Д.филол.н., профрессор, МГИМО МИД России \\ (Одинцовский филиал) \\ bosovalm@yandex.ru
}

Аннотация: В статье рассматриваются русские паремии, раскрывающие концепт «труд». Являясь одним из базовых компонентов любой картины мира, данный концепт наиболее полно отражает реалии жизни и быта соответствующего этноса и его культуры. Этим объясняется актуальность и значимость исследования. Анализ русских паремий показал, что они неоднозначно раскрывают отношение к труду в русской культуре: с одной стороны, $11 \%$ пословиц и поговорок утверждают положительное отношение к труду, с другой стороны, почти столько же русских паремий (10\%) реализуют негативное отношение к труду, отрицание его социальной значимости, даже презрение.

Ключевые слова: паремии, пословицы, поговорки, лингвокультурологический анализ, менталитет.

интерес. Результаты многочисленных исследований этнолингвистического и лингвокультурологического характера показывают, что данную лексико-семантическую общность единиц языка и культуры целесообразно рассматривать на основе их связей с действительностью и спецификой самых различных видов деятельности человека.

Данная статья посвящена изучению русских паремий о труде как стереотипов народного сознания, которые рассматриваются с лингвокультурологических позиций, что позволяет глубже и точнее отразить их содержательный аспект и выявить национально-культурную специфику. Это способствует дальнейшему теоретическому осмыслению взаимосвязи языка и культуры, а также более глубокому пониманию национального мировосприятия, отраженного в русской языковой картине мира, в основе которой лежит язык, отражающий общественноисторический опыт, как общечеловеческий, так и национальный. Все это определяет актуальность исследования.

Пословицы и поговорки можно определить как устойчивые выражения, характеризующиеся простой формой, точностью и лаконичностью, что обусловливает их запоминаемость и употребительность. Однако при всей своей схожести пословицы и поговорки также имеют и ряд различий, в частности, они не совпадают по структурной организации и содержанию. В нашем исследовании мы рассматриваем пословицы и поговорки 
как единый лексический пласт устойчивых выражений, широко употребляющихся в речи, отражающих стереотипы народного сознания и самобытность национальной культуры. Все исследуемые паремии раскрывают значение концепта «труд» в русском языке.

\section{Национальная культура через призму послович}

В данной работе пословицы и поговорки анализируются как неиссякаемый источник, копилка и сокровищница обычаев и традиций, знаний и сведений, умений и навыков, присущих русскому народу. «В идиоматике языка, то есть в том слое, который по определению национально специфичен, хранится система ценностей, общественная мораль, отношение к миру, к людям, к другим народам. Фразеологизмы, пословицы, поговорки наиболее наглядно демонстрируют и образ жизни, и географическое положение, и историю, и традиции той или иной общности, объединенной одной культурой» [1, с. 22]. Пословицы и поговорки, являясь неотъемлемым атрибутом народного фольклора и русской культуры в целом, несут в себе отражение жизни, образ мыслей и характер русской нации.

В каждом языке пословицы и поговорки являются языковым творчеством народа; они содержат как универсальные знания и представления, так и национально-специфические. Именно лингвокультурологический анализ национально-специфических пословиц и поговорок, отражающих национальную культуру и мировоззрение русского народа, лежит в основе данного исследования. Лингвокультурологический комментарий раскрывает национальные особенности восприятия внеязыкового факта, восполняет недостающие фоновые знания, необходимые для понимания незнакомых реалий, а также выявляет специфически национальные, культурно-бытовые или иные коннотации.

\section{^ингвокультурологический анализ русских послович и поговорок о труде}

Исследование проводилось на базе 198 паремий русского языка о труде, отобранных методом сплошной выборки из словарей пословиц и поговорок русского языка $[2,3]$. В ходе лингвокультурологического анализа русские паремии о труде были разделены на группы, раскрывающие отношение к трудовой деятельности в различных аспектах, которое закреплено в русской культуре. Далее будет рассмотрена каждая группа, их всего 12.

Прославление труда, положительная оценка трудового прочесса.

Многочисленную группу в исследуемом материале составили пословицы и поговорки, отображающие положительное отношение к труду, закрепленное в рус- ской культуре. В частности, было выявлено 22 паремии с положительной оценкой трудовой деятельности, что составило $11 \%$ от совокупного числа отобранных паремий: «Кто первый в труде, тому слава везде», «Кто любит труд, того люди чтут».

В группе пословиц и поговорок, выражающих положительное отношение к труду, особое внимание уделяется значению работы в повседневной человеческой жизни: «Дело учит, и мучит, и кормит»; «Работа да руки - надежные в людях поруки».

Труд восхваляется как антипод бездействию, что находит отражение в следующих примерах: «Без труда и отдых не сладок», «Кому работа в тягость, тот не знает радости», «Маленькое дело лучше большого безделья». Значение концепта «труд» в пословицах и поговорках значительно расширилось в XX в. Отныне его стали воспринимать не только как усилие и средство получения материальных благ, но и как источник морального удовлетворения: «За труд не бьют, а награды дают», «Кто в труде впереди, у того ордена на груди», «По труду и честь». Во всех этих пословицах и поговорках видно, что отношение человека к труду является своего рода критерием определения его значимости для общества. Таким образом, понятие «труд» перестало относиться к естественным, первоочередным потребностям личности, ему были приданы идеологические функции [4, с. 90].

Зависимость результатов труда от качества его выполнения (добросовестность, внимательность, аккуратность, тщательность).

Довольно многочисленная группа (39 примеров 19,6\%) представлена пословицами и поговорками, указывающими на прямую связь затраченных усилий и результатов работы. Эта мысль находит отражение в следующих изречениях: «Как потопаешь, так и полопаешь», «Летом не вспотеешь, так и зимой не согреешься». Все эти пословицы приводят к умозаключению о том, что «Высокий результат дается исключительно высококачественным трудом» [5, с. 159].

В паремиях русского языка о труде нашла отражение и мысль о том, что к делу нужно относиться с полной мерой ответственности: «Дела сами не ходят - их вести надобно». Паремии с таким внутренним подтекстом часто содержат ценное наставление о том, что нельзя перекладывать ответственность за результаты своей работы на кого-либо. Хочешь получить хороший результат - сделай работу самостоятельно: «Свой хлеб сытнее», «Живи своим умом и своим горбом», «Тот и господин, кто все может сделать один». Рассчитывать нужно исключительно на свои силы.

Особое внимание в русской культуре уделяется сво- 
евременному выполнению работы: «Вразумись здраво, начни рано, исполни прилежно!», «Какая пташка раньше проснулась, та скорее и корму нашла», «Рано вставши, больше наработаешь».

\section{Осуждение болтунов в труде.}

Чрезмерная болтливость никогда не одобрялась в русском обществе, что подтверждается наличием 16 примеров (8\%) в нашем материале, представляющих осуждение говорливости: «Легко сказка сказывается, да не скоро дело делается», «Не спеши языком, торопись делом», «Языком чесать, только время терять». Некоторые пословицы из этой группы содержат указание и на то, что пустая болтовня только мешает выполнению работы. В них явно акцентируется предпочтительность действий разговорам: «Не по словам судят, а по делам», «Сказано - не доказано, надо сделать», «От слова до дела - бабушкина верста (сто перегонов)», «Речи слышали, а дел не видим».

Порицание лени и тех, кому это качество присуще.

В пословицах и поговорках русского народа часто предметом осуждения выступает также лень, нежелание делать ту или иную работу (23 примера, 11,6\%). Человек, наделенный таким пороком, согласно широко распространенному в народе мнению, не одобряется, заслуживает негативного отношения. Лень и безделье, как с легкой иронией, так и с едким сарказмом, высмеивается во многих изречениях: «Лежа, пищи не добудешь», «Лежа на боку, не заработаешь и на понюшку табаку» и многие другие. В них праздному человеку дается оценка как «пустышке», а порицание самой лени, как специфического свойства человеческого характера, часто проявляется через призму иронии. Иными словами, лень высмеивается как порок. Это можно заметить в следующих примерах: «Кто пораньше встает, тот грибки берет, а ленивый да сонливый идут следом за крапивой», «Кто ленив сохой, тому весь год плохой», «У ленивой пряхи и для себя нет рубахи», «Проглотить-то хочется, да прожевать лень».

Трудолюбие подразумевает активность. У трудолюбивых людей любое дело спорится, буквально горит в руках: «Кто любит трудиться, тому без дела не сидится», «Клади картошку в окрошку, а любовь - в дело», «Была 6 охота - заладится и работа». В свою очередь, безделье очень часто на Руси ассоциировалось с пассивностью, что отразилось в следующих пословицах: «Ест за вола, а работает за комара», «Живет на горке, а хлеба ни корки». В пословичных изречениях этой группы явно делается акцент на то, что любому труду бездельники предпочтут еду и сон: «На работу он среди последних, а на еду - среди первых», «Много спать - дела не знать». Эти пословицы являются косвенным подтверждением того факта, что ленивые люди не видят необходимости в труде, если его можно перепоручить кому-нибудь другому, живут за счет усилий других людей: «Белые ручки чужие труды любят». Во многих паремиях нашего материала так же подчеркивается и тот факт, что во время трудовой деятельности в душе человека взращивается зерно добра и нравственности. При этом лень противопоставляется этому свойству труда как категории, относящейся к темным силам [6, с. 108], к примеру: «Безделье - мать всех пороков», «Лень до добра не доводит», «Черт найдет занятье для ленивых рук», «На безделье всякая дурь в голову лезет».

С другой стороны, в русских пословицах и поговорках о труде также осуждается и чрезмерная суетливость и неоправданная спешка. Поспешность в работе является нежелательным качеством, не способствующим качественному выполнению дела. «Делали наспех, а сделали на смех»; «Скоро только блох ловят», «Был такой, что торопился, да скоро умер» - все эти изречения подчеркивают негативное влияние спешки на конечный результат.

\section{Этапы трудовой деятельности.}

Ряд пословичных выражений (15 примеров, 7,8\%) указывает на важность выполнения каждого этапа работы, акцентируя внимание на начало, конец: «Почин дороже всего», «Дело без конца - что лошадь без хвоста», «Не начавши, думай, а начавши - сделай», «Не мудрено начать - мудрено кончить». Здесь подчеркивается и важность наличия интереса к работе, энтузиазма при ее выполнении и тщательного добросовестного доведения начатого дела до конца.

\section{Роль орудия труда в трудовом прочессе.}

В русском языке можно выделить и обширную группу пословиц и поговорок, в которых оценивается роль орудий труда в трудовом процессе. Количество таких выражений в нашем исследовании составило 8\% . Они указывают на важность и значимость наличия тех или иных инструментов для достижения высоких результатов. В них отмечается, что без наличия соответствующих орудий труда, инструментов нет и надлежащей работы: «Мастер глуп - нож туп», «Без снасти и вши не поймаешь», «Без снаряда и лаптя не сплетешь», «Голыми руками ежа не ухватишь». Все эти изречения указывают на значимость орудий труда в работе, поскольку без них трудовой процесс невозможен в принципе. При этом в пословичных изречениях из этой подгруппы также превозносится и умение обращаться с инструментом, к примеру, «Мастер за дело берется смело».

Нередко в пословицах так же обращается внимание и на то, что состояние инструментов мастера напрямую свидетельствует и об его отношении к работе: «Хочешь 
сделать работу - сначала наточи инструменты», «На острую косу много сенокосу». Таким образом, порядок и бережное обращение с инструментами становится своего рода лицом профессионализма мастера, демонстрирует его отношение к своим непосредственным обязанностям, работе.

Профессионализм мастера - гарантия качественного выполнения работы.

В русских паремиях (11 примеров, 5,5\%) прослеживается также указание на прямую зависимость результатов работы от профессиональных навыков мастера, важность наличия тех или иных умений и слаженности действий в процессе работы: «В иных руках и горсть пыли в золото превращается»; «Не кует железа молот, кует кузнец» и наоборот «Плохому танцору одежда мешает». Следует, однако, обратить внимание на тот факт, что эта группа весьма не многочисленна, также как и следующая, указывающая на связь благосостояния с результатом трудовой деятельности.

Материальное благосостояние - важнейший результат трудовой деятельности.

В исследуемом материале имеются всего 6 примеров (3\%) пословиц и поговорок о труде как источнике заработка, способе получения материальных благ: «Без труда меду не едят», «Кто не ленив пахать, тот будет богат!». А такие изречения, как «За бесплодный труд и спасибо нет», «Труд без пользы - то же безделье», «Три дни молол, а в полтора съел» еще раз напоминают, что бесполезная работа, не приносящая должных результатов, не будет по достоинству оценена и вознаграждена.

\section{Приоритетность труда.}

В отдельную группу выделены паремии, несущие в себе мысль о важности приоритетного отношения к труду (8 примеров, 4\%). Они содержат не только позитивную оценку труда как такового, но и акцентируют внимание на предпочтительности трудовой деятельности досугу. В таких выражениях подчеркивается важность и главенствующее место работы в жизни каждого человека: «Шутке - минутка, а делу - час», «Пей, гуляй, а работу знай», «После дела и гулять хорошо». Русские пословицы и поговорки призывают человека отдыхать, не думая о работе, только после успешного ее выполнения: «В субботу - на работу, а в воскресенье - на веселье»; «Сделай дело, гуляй смело». При этом отдых воспринимается как особого рода благо, заслуженная награда за труд. Так, «Без отдыха и конь не скачет», «И дурак знает, что воскресенье - праздник», «И коню хоть раз в году положен отдых». В целом, повседневная жизнь народа на Руси была очень тяжелой, и «праздной» она не бывала даже в праздничные дни (уход за скотом, работа по дому - все это требовало достаточно больших усилий). Об этом говорят такие русские пословицы: «А когда досуг-то будет? - А когда нас не будет», «Будет досуг, когда вон понесут», «На том свете отдыхать будем».

Можно сказать, в пословичных изречениях русского народа издавна прослеживается мысль о том, что красота и сила человека наиболее ярко проявляется в труде. Трудовой процесс является, в частности, той специфической средой, где зарождаются творческие способности, и проявляется вдохновенье человека. Благодаря этому свойству труда на протяжении долгих лет он остается одной из важнейших нравственных ценностей русской нации.

Трудолюбие испокон веков пользовалось уважением в народе, что нашло свое отображение в таких выражениях, как «Умелец и рукодельник и себе, и людям радость несет», «Работай более, и тебя будут помнить долее», «Чтоб в почете быть, надо труд свой полюбить».

Тем не менее, в нашем материале есть примеры, указывающие на то, что высокий материальный достаток на Руси часто ассоциировался с бесчестием и грехопадением. В народе бытовало убеждение, что упорством и старанием богатства не нажить: «От трудов праведных не нажить палат каменных», «Денег нет, так подушка под головой не вертится», «В аду не быть - богатства не нажить».

Таким образом, в русских пословицах и поговорках работа, с одной стороны, является неким благом, ее важность в человеческой жизни всячески подчеркивается. Но, с другой стороны, честный труд не является синонимом состоятельности, награда за труд непосредственно для работника очень часто бывает неоправданно низкой.

\section{Отрицательная оценка трудового прочесса.}

Немалая доля русских паремий выражает отрицательное отношение к труду (22 примера, 11\%). Довольно часто в этих пословичных изречениях проявляется склонность к преувеличению, гиперболизации при обозначении объема работы: «На мир не наработаешься», «Господской [барской] работы не переделаешь», «Весь мир не обвяжешь».

Довольно много русских пословиц и поговорок выражает и стремление избежать тяжелой работы: «Хочется есть, да не хочется слезть». Более того, в отдельных изречениях делается акцент и на желании иметь успех, достичь высоких результатов без напряжения и каких-либо явных усилий: «Нам бы так махать, чтобы мозолей не набивать».

Более того, в отдельных примерах русских пословиц и поговорок явно прослеживается и желание отложить сроки выполнения работы, пренебрежительное отношение к труду: «Работа не волк, в лес не убежит», «Работа не 
черт, в воду не уйдет», «Дела не голуби - не разлетятся». В некоторых пословицах и поговорках даже осуждается чрезмерное рвение к работе: «Ретивая лошадка недолго живет», «Лошадка с ленцой хозяина бережет», «Работа дураков любит».

К паремиям о труде с отрицательной коннотацией можно также отнести пословицы и поговорки, несущие в себе мысль о несоответствии награды за труд вложенным усилиям, к примеру: «От работы (сохи) не будешь богат, а будешь горбат», «Золото моем, а сами голосом воем», «Из-за хлеба на квас не наработаешь». Помимо этого, также ставится под сомнение и польза труда. В совокупности это складывается в негативную оценку трудовой деятельности как таковой: «Работа молчит, а плечи кряхтят», «Из топора не богатеют, а горбатеют», «Заработали чирей да болячку да третий горб».

Важно отметить, что такое негативное отношение к труду обусловлено социально-историческими причинами. Издавна на Руси работа не приносила ни благосостояния, ни высокого социального статуса в обществе, ни независимости. Да и главный труженик - крестьянин уважением не пользовался. Положение не изменилось и в советское время. Работа не выполняла свою прямую задачу - быть средством удовлетворения потребностей личности. Многие люди страдали от постоянного недостатка самого необходимого. Отсюда и неприятие труда [5, с. 159]

Гендерные различия в труде (9 примеров, 4,5\%).

Анализ пословиц и поговорок можно провести и в разрезе гендерного аспекта, рассматривая отношение к трудовой деятельности через призму понятий «мужчина» и «женщина». При этом во многих паремиях русского языка образ мужчины ассоциируется с пассивностью и ленью. Русский мужик вечно голодный и постоянно лежащий на печи, к примеру: «Мужик на счастье сеял хлеб, а уродилась лебеда», «Мужику не наносить и мешком, что баба натаскает горшком», «На авось мужик и пашню пашет». Как видно из примеров, мужчине отводилась пассивная роль. Он не деятель, не хозяин, от его ума только горе, а работа, как правило, не приносит удовлетворения. Активность была прерогативой женщины, хранительницы очага: «Мужик без жены, что гусь без воды» [7, с. 165].

При всем этом в народе существуют и пословицы, в которых восхваляется образ мужчины-труженика: «Мужику одна забота, чтобы шла путем работа», «Мужик проказник, работает и в праздник».

Использование образов животных в пословицах о mpyдe.

Очень широкое распространение в пословицах и поговорках русского народа получила практика ото- ждествления тех или иных присущих человеку качеств с образами животных. К примеру, иносказательными символами трудолюбия и добросовестного отношения к труду традиционно выступает образ пчелы. Такие качества пчелы, как неутомимость в труде, бережливость, аккуратность, издавна восхваляются в народе: «Трудолюбивее пчелы никого нет», «Пчела далеко за каплей летит», «Мала пчелка, да и та в трудах». Трудолюбие в русских пословицах и поговорках довольно часто отождествляется и с такими представителями животного мира как вол, ишак, муравей: «Муравей не велик, а горы копает», «Вола в гости зовут не медлить, а воду возить».

В свою очередь, нерасторопность в труде и чрезмерная медлительность во многих русских паремиях отождествляется с образом медведя: «Ловит, как медведь перепелку», «Неповоротлив как медведь» и др.

В результате лингвокультурологического анализа русских пословиц и поговорок, выражающих концепт «труд», можно сделать вывод о том, что труд, как одна из важнейших нравственных ценностей нации, неоднозначно выражен в русских паремиях. С одной стороны, трудолюбие всегда было и является в почете в русской культуре, в то же время, 10\% отобранных паремий выражают пренебрежительное отношение к делу и желание отложить сроки его выполнения. Во многих демонстрируется отсутствие энтузиазма в работе, содержится мысль о несоответствии награды за труд приложенным усилиям, а так же говорится о бесполезности трудовой деятельности как таковой. В русских пословицах и поговорках трудовая деятельность довольно часто характеризуется как явление тяжелое и изнуряющее. В большинстве случаев работа не приносит радости или удовлетворения [8, с. 211]. Этим, видимо, и объясняется наличие в русском менталитете уничижительного отношения к труду и стремления достичь высоких результатов, не прилагая больших усилий.

\section{Зак^ючение}

Большое значение для познания прошлого и истоков культуры имеют паремии, включающие пословицы и поговорки, которые по праву являются своего рода зеркалом многовековой народной мудрости. Лингвокультурологический анализ паремий отдельно взятой нации способствует выявлению национально-культурных ценностей и убеждений народа, а также его национальнокультурной специфики.

Исследование русских паремий о труде в лингвокультурологическом аспекте показало, что наряду с положительным отношением к труду, включающем одобрение качественного, добросовестного, профессионального труда, в исследуемом материале имеется значительное количество примеров (10\%), отражающих негативное 
отношение к труду как к деятельности чрезмерно сложной, изнуряющей, бесполезной, не приносящей благополучия, радости и удовлетворения. Тем не менее, при достаточно распространенном негативном отношении к трудовой деятельности, которая большей частью была принудительной и не сулила человеку достойной жизни, на Руси издавна было много высококлассных умельцев и мастеров, существовавших как будто вне системы, им не способствующей. Такое неоднозначное отношение к труду в России объясняется вековой несправедливостью, которую испытывали крестьяне и другой рабочий люд в связи с тяжелыми историческими обстоятельствами.

Безусловно, пословицы несут в себе глубокий смысл и передают важные нормы и традиции народа, а также те изменения, которые происходят в постоянно развивающемся обществе. Так, в условиях современного мира происходят существенные изменения в отношении к труду, оценке его роли в русском социуме, что также нашло отражение в русских паремиях более позднего периода.

Значимость исследования заключается не только в уточнении понимания ценностной картины мира носителей русского языка, определении этнических и социокультурных особенностей русских паремий о труде, но и в возможности использовать полученные сведения на практике: в преподавании русского языка, а также теоретических курсов по лексикологии, лингвокультурологии и межкультурной коммуникации.

\section{ЛИТЕРАТУРА}

1. Тер-Минасова С.Г. Язык и межкультурная коммуникация. М., 2000. - 80 с.

2. Даль В.И. Пословицы русского народа. - М.: ОЛМА-ПРЕСС, 2010. - 608 с.

3. Жуков В.П. Словарь русских пословиц и поговорок. М.: Русский язык, 1993. - 538 с.

4. Иванова Л.Е., Самохина Л.А. Концепт «труд» в русской языковой картине мира // Язык и межкультурная коммуникация. - Уфа: БГПУ, 2002. - №2.- С. 89-90.

5. Жданова В.В. Пословицы и поговорки как источник изучения русского культурно-языкового сознания // Культурные слои во фразеологизмах и дискурсивных практиках М., 2012. -№ $9-$ С. 151-160.

6. Каримова Р.Х. Способы отражения концепта «ленивый» в пословицах неродственных языков //Коммуникативно-функциональное описание языка. Уфа, 2010 № 1. - С. 105- 110.

7. Эмирова А. Оппозиция «мужчина-женщина» в русской фразеологии// Грани слова: Сб. науч. статей. М., 2011. - №1- С. $165-169$.

8. Иванова Е.В. Мир в английских и русских пословицах. - Спб.: Питер, 2010. - 292 с.

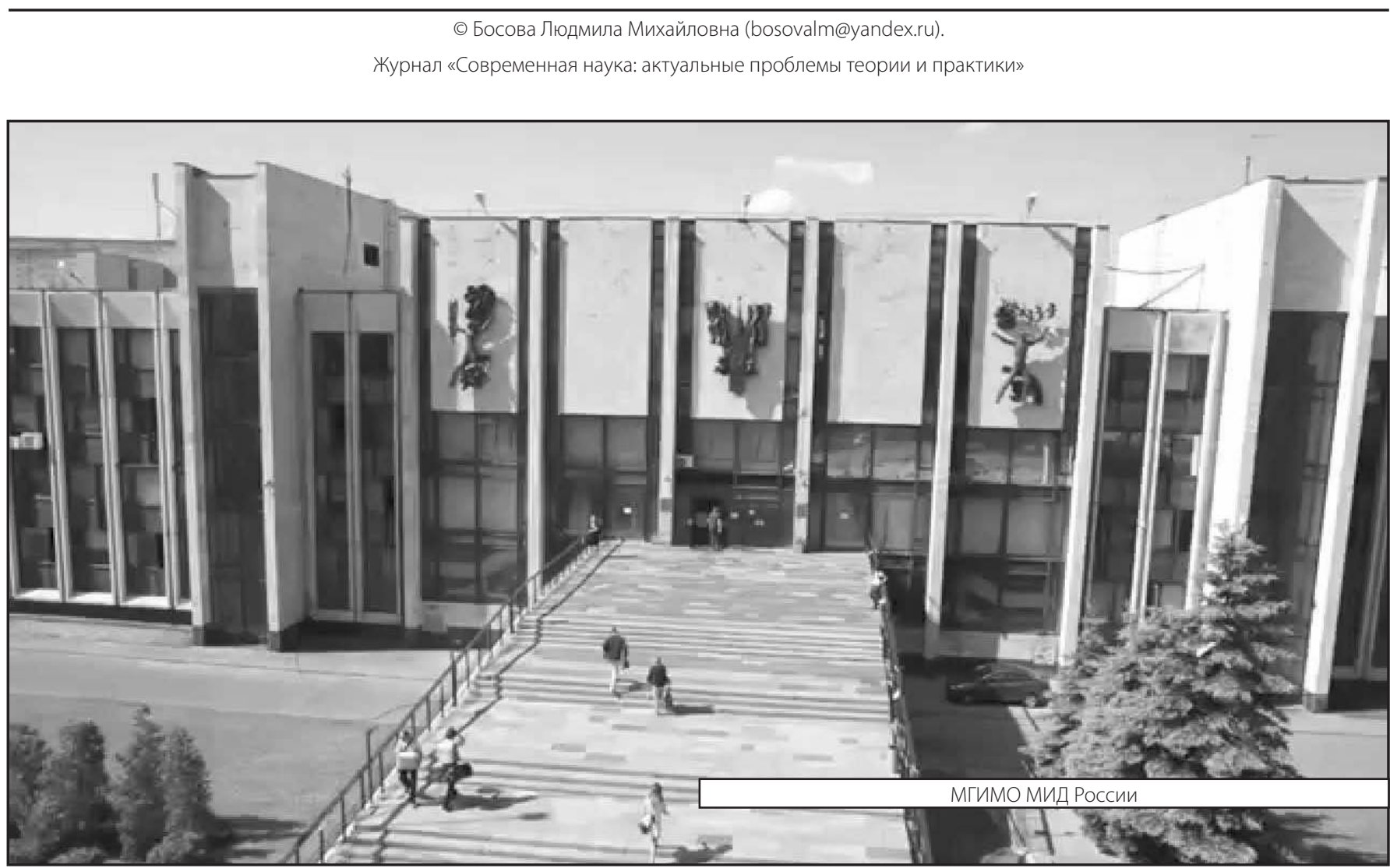

